Comunicación y política: ejercicios reflexivos 


\title{
Acción, subjetividad política, democracia y resistencia. Una lectura desde la antropología política de $\mathrm{H}$. Arendt
}

\author{
Rolando Chaparro \\ (Universidad de los Llanos, Colombia)
}

Recibido: $21 / 7 / 2015$

Aprobado: 22/9/2015

Resumen. Producto asociado de la tesis doctoral "Prácticas políticas 2.0: mecanismos de participación, acción y resistencia en red", este documento tiene como punto de partida la antropología política de Hannah Arendt, quien, al distinguir labor, trabajo y acción, le otorga a esta tercera dimensión constituir el significado mismo de humanidad. Y con ello, le adjudica a la acción, la acción política, el elemento definidor de la condición humana. En un segundo apartado, se argumentan las razones que limitan el concepto de ciudadanía como categoría conceptual que da cuenta del actuar de sujetos y movimientos sociales en el marco de las sociedades contemporáneas, para proponer una reflexión sobre la democracia radical y las formas de resistencia en la denominada sociedad red. Palabras clave: acción / política / resistencia / democracia (Tesauro de la Unesco)

\section{Action, Political Subjectivity, Democracy and Resistance. A Reading from the Political Anthropology of $\mathrm{H}$. Arendt}

\begin{abstract}
Авsтract. Stemming from the doctoral thesis "Political Practices 2.0: Mechanisms of Participation, Action and Resistance Network", this paper takes as it starting point Hannah Arendt's political anthropology, that by distinguishing labor, work and action, puts the latter at the very center of the meaning of humanity. Therefore, it proposes action, namely political action, as a defining element of human condition. In the second section, the paper addresses the factors that limit the concept of citizenship understood as a conceptual category that accounts for the acts of individuals and social movements in the context of contemporary societies. The section aims at proposing a reflection on democracy and radical forms of resistance in the so-called network society.
\end{abstract}

Key words: action / politics / resistance / democracy (Unesco Thesaurus) 
Sin la acción, sin la capacidad de comenzar algo nuevo y de este modo articular el nuevo comienzo que entra en el mundo con el nacimiento de cada ser humano, la vida del hombre, que se extiende desde el nacimiento a la muerte, sería condenada sin salvación.

Hannah Arendt

\section{Hannah Arendt y la (política) condición humana}

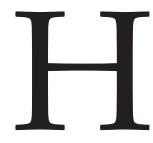

annah Arendt siempre se entendió como una outsider, una paria según sus propias palabras, no solo por su condición de judía no practicante en un mundo sobrecogido por las atrocidades del holocausto de la Segunda Guerra Mundial, sino ante todo por su condición de mujer en un ámbito abiertamente masculino como el filosófico y por no apegarse a un sistema de pensamiento en particular o a una escuela determinada. De ahí su condición de segregada, de relegada, de excluida: la de quien deambula por el mundo bajo la brillante luz de un pensamiento inclasificable, miembro de una legión de intelectuales perseguidos o exiliados por el nazismo. Una "mensajera del infortunio", como dijera de ella Bertolt Brecht.

De aquí, probablemente, esa visión apátrida de la existencia, esa mirada de extranjera desde el propio mundo que prefiere no estar ligada a nada y, por el contrario, caminar los siempre escabrosos terrenos intelectuales de manera libre y enseñar con el ejemplo (en su sentido más literal) que todos podemos practicar el pensamiento crítico sin ser necesariamente pensadores profesionales, intelectuales o filósofos. Y una puntualidad más: que en la posibilidad que tenemos todos de poder defender nuestro particular punto de vista no cabe la intromisión de la moral asociada a la cultura o la educación, pues incluso las personas más educadas pueden ser capaces de las mayores atrocidades, tal como ella misma pudo verificar y señalar con las lecciones del nazismo y, por extensión, con la evidencia de toda forma de totalitarismo y que hizo parte fundamental de su programa intelectual.

La lección del episodio de Adolf Eichmann en el famoso juicio que lo condujo a la horca así pareciera demostrarlo: a pesar de las serias contradicciones con que sus compatriotas e incluso sus más cercanos amigos recriminaron la forma de pensar de Arendt respecto de sus artículos para The New Yorker, ella mantuvo la posición que su reflexión le proporcionó: Eichmann no era más que un burócrata que seguía instrucciones, apegadas por supuesto a la ley del Partido Nacional Socialista $y$, por tanto, no un ejecutor monstruoso de las atrocidades del régimen sino un triste, un banal funcionario que cumplía con precisión las demandas institucionales. La banalidad del mal, la no radicalidad del mal, la carencia absoluta de cualquier profundidad del mal es la que expone en sus trabajos, seguidos por una exponencial 
andanada de sus compatriotas, sus detractores, incluso de sus amigos. Esa muestra indudable del carácter autónomo del pensamiento arendtiano contrasta afirmativamente con la fuerza de su reflexión, quizás una de las más influyentes del siglo XX, tanto en el campo de la educación como en el de la moral. Pero es justamente el terreno de la política (y no exactamente en la filosofía política, pues, como se dijo anteriormente, su clasificación no llegaba al rango de filósofa) el que le permitirá efectuar algunas de sus más importantes contribuciones a la comprensión de los fenómenos que atribularon la segunda mitad del siglo XX: el totalitarismo, el mal, la culpa del pueblo alemán, la condición humana.

Pensar aquellas expresiones horrorosamente concretas la hizo alejarse de la metafísica y de la "sabiduría de los siglos" y, por el contrario, acercar su pensamiento a la realidad padecida por su pueblo. En palabras de Bárcena (2006):

O, lo que es lo mismo, se trataba de seguir pensando justamente en el seno de una brecha, de una grieta o de una hendidura abierta en el mismo centro del tiempo, y de pensar esa grieta, que toma la forma de un acontecimiento. Mas ¿cómo pensar en ese espacio roto, en esa hendidura donde parece que el sujeto que piensa se instala en una suerte de presente continuo? ¿Cómo pensar si el pasado -que es un 'ya no'- nos presiona al mismo tiempo que el futuro -que es un 'todavía no'-? ¿Cómo pensar y entender un acontecimiento que rompe con los fundamentos tradicionales (éticos, ju- rídicos, antropológicos, etcétera) que nos habían ayudado hasta ahora a orientarnos en el mundo, y también en el pensamiento? (p. 50)

Estas preguntas, que animaban el programa intelectual de quien alguna vez dijera "lo que yo quiero es comprender", devienen experiencia de manera más o menos congruente, pues ya en 1958 lo afirmaba enfáticamente al referirse a la acción:

Si la acción como comienzo corresponde al hecho de nacer, si es la realización de la condición humana de la natalidad, entonces el discurso corresponde al hecho de la distinción y es la realización de la condición humana de la pluralidad, es decir, de vivir como ser distinto y único entre iguales. (Arendt, 2013, p. 202)

Es decir, el simple hecho de nacer humanos no nos determina humanos: la condición humana no está condicionada por la naturaleza humana. Lo humano de lo humano es el trabajo, la acción con la que el hombre ejerce su presencia en el mundo y no solo en los procesos biológicos del cuerpo, a diferencia del trabajo, que le añade (en el pensamiento arendtiano) objetos al mundo común de las cosas. Y con ello, el hombre es un fabricador, un creador. Un poeta que hace de la acción un acto creador, y no simplemente una repetición de su labor, fácilmente instrumentalizada y opacada, como sucede en la actualidad del capitalismo de consumo.

Se comprende de esta forma el porqué de su afirmación según la cual 
“el pensamiento era secundario al discurso, pero discurso y acción se consideraban coexistentes e iguales, del mismo rango y de la misma clase" (Arendt, 2013, p. 39), con lo cual insiste en la importancia de la acción sobre la contemplación y no solo como facultades humanas, sino acaso como formas muy diferentes y particulares de vida.

Ello lo hace al comparar labor, trabajo y acción en La condición humana (2013), y al otorgar a la acción una preponderancia sobre las otras formas de actuación humana y que definen la circunstancia particular del hombre sobre otras especies. En su reflexión, Arendt distingue labor, trabajo y acción definiendo la primera de esas tres actividades, y que ella considera fundamentales, la labor, como la actividad que se encuentra en correspondencia con el proceso biológico, natural, orgánico del cuerpo humano. Así pues, la labor estaría relacionada con los procesos vitales humanos, como respirar o alimentarse.

A su turno, la actividad denominada trabajo está relacionada con lo no natural de la exigencia del hombre y que remite a la artificialidad del mundo de las cosas que, por supuesto, difieren de las circunstancias naturales: el trabajo, visto de esta manera, posee un carácter procedimental dominado por la racionalidad medios-fines.

En relación con la acción, Arendt (2013) la define como

la única actividad que se da entre los hombres sin la mediación de cosas o materia, corresponde a la condición humana de la pluralidad, al hecho de que los hombres, no el Hombre, vivan sobre la Tierra y habiten el mundo. (p. 22)

Y continúa:

Mientras que todos los aspectos de la condición humana están de algún modo relacionados con la política, esta pluralidad es específicamente la condición -no sólo la conditio sine qua non, sino la conditio per quam-de toda vida política. (p. 22)

Se reconocen acá los ecos de la Grecia clásica, en el modo en que la pensadora define la política en su relación con la vida en la polis, no solo por el hecho de recordar que todo se decía por medio de palabras y de persuasión sino, fundamentalmente, porque en esta actividad no se encontraba cabida a la fuerza y la violencia. Todo lo anterior se presenta en virtud de que el hombre se considera en Arendt no solo el zoon politikon propuesto por Aristóteles sino zoon logon ekhon, un ser vivo capaz de discurso, que se opone a las manifestaciones de los gobiernos de nadie (notablemente, la burocracia), que como forma más social de gobierno puede resultar una de sus versiones más crueles y tiránicas, como intentó demostrarlo en su reportaje al juicio de Adolf Eichmann.

En este punto, es necesario recordar que la autora de Hannover manifestó:

La sociedad espera de cada uno de sus miembros una cierta clase de conducta, mediante la imposición de innumerables y variadas normas, todas 
las cuales tienden a 'normalizar' a sus miembros, a hacerlos actuar, a excluir la acción espontánea o el logro sobresaliente. (Arendt, 2013, p. 51)

Como se ve, la actividad denominada acción define la pluralidad de los hombres y se constituye en la condición humana por excelencia, cuyo producto es el resultado no de la definición y la concreción de leyes universales para generar comunidad sino de un grupo históricamente construido. Dice Arendt, finalmente, en su conferencia “Labor, trabajo y acción” de 1957:

En otras palabras, la vida activa no es solamente aquello a lo que están consagrados la mayoría de los hombres, sino también aquello de lo que ningún hombre puede escapar totalmente. Porque está en la condición humana que la contemplación permanezca dependiente de todos los tipos de actividades; depende de la labor que produce todo lo necesario para mantener vivo el organismo humano, depende del trabajo que crea todo lo necesario para albergar el cuerpo humano y necesita la acción con el fin de organizar la vida en común de muchos seres humanos de modo que la paz, la condición para la quietud de la contemplación, esté asegurada.

Este trabajo, en este sentido, se hace tributario de la tarea intelectual de Arendt en el sentido de otorgar a la acción un lugar de privilegio entre las actividades de la 'condición' humana (y no solo de la 'naturaleza' humana, como advertía la autora), es decir, que nos señala definitivamente como seres humanos y nos distingue como especie, lo que no solo le confiere a la política un lugar de privilegio que encara sus actuales y podríamos decir naturales refutaciones (hoy que la política es vista casi con desprecio o sospecha por muchos y que a algunos sectores de la población -notablemente los jóvenes- incluso se los tilda de apáticos hacia su ejercicio), sino que en tanto realidad humana, reconoce a la política obediente de la acción y al discurso. De esta forma, Arendt evade el desarraigo del hombre por el animal laborans como sujeto de necesidades del mundo moderno. El hombre, pues, que se debe recuperar en las postrimerías del totalitarismo (fundamentalmente por la acción decisiva del nazismo) y encaminarlo hacia el ejercicio de las democracias parlamentarias no como un ser que se comporta, sino como un ser que actúa como consecuencia de su situación en el mundo.

\section{La ciudadanía: entre límites y fronteras}

Con el declive de los Estados nacionales, la idea de ciudadanía anclada a los compromisos de los sujetos a lo público se encuentra, al parecer, erosionada y afectada. $\mathrm{O}$ por lo menos se ha visto notoriamente cuestionada. Ciertamente, situaciones que se ubican en el filo de este nuevo siglo y que lo revisten de su particularidad afectan la idea de ciudadanía proveniente de la modernidad: y es que a juicio de muchos la mutación que han sufrido tanto el concepto como la práctica de la 
ciudadanía -como producto de múltiples situaciones que se exponen más adelante, y de manera notable como producto de la reducción a mercado del Estado nacional y su reconfiguración en los gobiernos neoliberales-, ser ciudadano hoy no tiene el mismo significado que el otorgado por las nacientes repúblicas liberales del siglo XVII en el sentido de otorgar reconocimiento social y jurídico para que una persona se reconozca como sujeto de derechos y deberes. La ciudadanía vinculada a la nacionalidad.

Entre los varios fenómenos asociados a este malestar, definitivo en esta transformación, podemos encontrar algunos otros puntos:

\section{- Crisis de las instituciones sociali-} zadoras clásicas. La transformación/ crisis de la familia (de la convencional familia nuclear a la familia extensa, y más allá a la estructura familiar monoparental e incluso la familia de carácter homoparental) coincide con el malestar que la escuela, como instituciones socializadoras básicas de la sociedad, genera en el seno del grupo social: temas asociados a la seguridad social y personal, el individualismo, la insolidaridad, la soledad, deserción y bajo rendimiento escolar o la fragmentación social y sus conexiones con estas dos instituciones básicas del sistema social, dan cuenta de cierta suspicacia con la que se relatan los alcances de la escuela y la familia en la actualidad. Y de allí, la pregunta por su despliegue en la configuración de ciudadanía activa en los más jóvenes, en los "recién llegados" según $\mathrm{H}$. Arendt. Para Borja (2007), por ejemplo, queda claro que

sin instituciones fuertes y representativas no hay ciudadanía. El status, los derechos y deberes que lo componen, reclaman instituciones y políticas públicas para garantizar el ejercicio o el cumplimiento de los mismos. La igualdad requiere una acción pública permanente, las libertades urbanas soportan mal las exclusiones que generan las desigualdades económicas, sociales o culturales. La ciudadanía va estrechamente vinculada a la democracia representativa y participativa para poder realizar sus promesas. A menos democracia, más desigualdad. (p. 7)

Cita de la cual podría surgir un repertorio de interrogantes: ¿quién forma en democracia, en ciudadanía?, ¿cumplen la familia y la institución escolar el papel de formar ciudadanos aplicados para el ejercicio democrático, la solidaridad (la "virtud sospechosa", para Adela Cortina [2010]), la toma de decisiones en colectivo?, ¿acaso las preocupaciones de la escuela por la competitividad, la eficiencia, el control y el adocenamiento han desnaturalizado, o por lo menos desviado, sus propósitos?, ¿cómo vincular escuela y familia en la configuración de una sociedad democrática?

- Desconfianza de la política institucional. Malestar de la política 
partidista. Cierto escepticismo por las actuaciones de la democracia representativa aflora en el discurso político contemporáneo en donde existe una preocupación porque el modelo representativo está centrado casi exclusivamente en la actividad de los representantes, mientras que el papel de los representados está reducido a la participación electoral que se agota en la selección de los gobernantes. Amén de ello, subsisten críticas a los partidos políticos por no estar en sintonía de las expectativas populares y comunitarias: en Colombia, por ejemplo, los partidos políticos tradicionales, el Partido Liberal y el Partido Conservador, nacidos de los esfuerzos de la democracia liberal y como producto de las luchas de independencia, han debido reconfigurar prácticas y discursos para atraer el interés de un electorado cada vez más escéptico e incrédulo que ha visto cómo sus idearios tradicionales se retuercen para satisfacer las expectativas de la política institucional y se han ensamblado a manera del puzle en alianzas, colectivos, grupos o movimientos que se recombinan dependiendo de los juegos del ejecutivo de turno y de las dinámicas siempre fluidas aunque voraces de los apetitos burocráticos. En otro espectro de este malestar quedan las incertidumbres frente a la escasa o nula rendición de cuentas (accountability) que las representaciones hacen de su ejercicio, que en la teoría minimalista se concentran en las elecciones y los efectos que generan estas inacciones en el cumplimiento de las tareas democráticas ciudadanas.

\section{- Reducción del tamaño del Estado} (neoliberalismo). Quizá la tarea más emblemática, y en tal sentido la mejor cumplida, de las formas más conservadoras del liberalismo económico haya sido la de reducir el tamaño del Estado a proporciones de simplificación: con la excusa (muy bien gana$\mathrm{da}$, hay que decirlo) de su ineficiencia por la excesiva cuota burocrática, de la corrupción rampante en la actuación de sus funcionarios, de la necesidad de constituir espacios más flexibles para la circulación de los capitales trasnacionales, la ampliación de los mercados a escala planetaria y la renovación permanente de la oferta en tiempos de hiperconsumo. El sacrificio del papel del Estado en pos de tales iniciativas condujo, necesariamente, a desbastar de manera rigurosa, sistemática y progresiva sus acciones, las cuales serían remplazadas -según los sacerdotes del nuevo orden- por la lógica todopoderosa, irrefutable y omnímoda del mercado. Y una vez allí, ¿cuál sería el papel del ciudadano?, ¿qué función tiene un ciudadano sin Estado?, ¿qué lo remplaza? Interrogantes que dan cuenta no solo de una preocupación y una errancia reflexiva, sino de los contrastes que la situación generó: la emergencia de megacoporaciones arbitradas por la libre competencia y la ideología felicista (el Planeta Hollywood, el Planeta Facebook, 
el Planeta Simpson, pero también Lexcorp, Oscorp ${ }^{1}$, AOL, Disney o McDonalds) y, en la otra esquina, la renovación de los arraigos locales: identidades comunitarias, barriales (maras, pandillas, grupos, galladas), culturales, religiosas o políticas que ya no pasan por los reconocimientos masivos sino por las coyunturas, las complicidades, las coincidencias.

\section{- Cultura y consumo: de ciudadanos}

a consumidores. El artículo 42 de la Constitución Política de la República Argentina -que reformó la preexistente a través de una constituyente en el gobierno de Carlos Ménem de 1994reza, en su sección sobre nuevos derechos y garantías:

Los consumidores y usuarios de bienes y servicios tienen derecho, en la relación de consumo, a la protección de su salud, seguridad e intereses económicos; a una información adecuada y veraz; a la libertad de elección y a condiciones de trato equitativo y digno.

Las autoridades proveerán a la protección de esos derechos, a la educación para el consumo, a la defensa de la competencia contra toda forma de distorsión de los mercados, al control de los monopolios naturales y legales, a la de la calidad y eficiencia de los servicios públicos, y a la constitución de asociaciones de consumidores y usuarios.

La legislación establecerá procedimientos eficaces para la prevención y solución de conflictos, y los marcos regulatorios de los servicios públicos de competencia nacional, previendo la necesaria participación de las asociaciones de consumidores y usuarios de las provincias interesadas en los organismos de control.

Ya nos había advertido García Canclini (1995) en el prólogo de su libro Consumidores y ciudadanos... que su tarea consistía en "entender cómo los cambios en la manera de consumir han alterado las posibilidades y las formas de ser ciudadano" (p. 29). Y con ello proponía superar el lugar común frente al consumo y, más allá,

deconstruir las concepciones que encuentran los comportamientos de los consumidores predominantemente irracionales y las que ven a los ciudadanos actuando en función de la racionalidad de los principios ideológicos (p. 32).

Para cualquiera de los casos, queda evidencia de la importancia que el consumo de productos (aunque también el de bienes y servicios) ha adquirido en la actualidad, ya sea otorgándole

1 OsCorp y LexCorp hacen parte, en el universo de los cómics, de las megacorporaciones que atentan contra la seguridad del planeta a escala global, justamente alentadas por las aventuras del capitalismo trasnacional de redes, informática y comunicación generalizadas. Sus precursores: Lex Luthor y Norman Osborn, archienemigos de Superman y el Hombre Araña, respectivamente. La literatura de cordel también narra desde la cotidianidad. 
rango constitucional (como ha sucedido en otros países de América Latina, por ejemplo en Colombia y Perú) o reconociendo su importancia en el ámbito académico. Ello no implica, como se podría objetar, la culminación de la tarea del ciudadano como soporte subjetivo de la nacionalidad y como elemento constitutivo del lazo social, sino su, digamos, devaluación frente a otras instancias y fenómenos presentes en sociedades contemporáneas.

\section{- Ampliación de visiones del mundo:} la mediatización. En sociedades poscapitalistas/posindustriales, en las que como se había planteado la ciudadanía se encuentra en crisis, la información constituye un elemento básico del cual subyace la comunicación, constituida en la actualidad en una preocupación a escala planetaria. Ciertamente, a medida que avanza el siglo XXI se ha convertido en un imperativo el hecho de que la comunicación se establezca como estrategia para la supervivencia y la continuidad del género humano -y no únicamente para justificar la premonición baconiana de "saber es poder"-, en la medida en que la comunicación y su sobreoferta en la sociedad de masas implica otras formas de relación y otro tipo de manifestaciones (corpóreas, gestuales, escriturales, orales) o nuevas formas de expresión, como en el caso de las nuevas oralidades de la comunicación hipertextual, las "gramáticas otras" de la narración audiovisual o la irrupción de formas alternativas a los repertorios simbólicos tradicionales. $\mathrm{Y}$ aunque ello exprese afirmativamente las tendencias comunicacionales que se integran, según la clásica metáfora empleada por Umberto Eco, en el afán de los científicos sociales y de ciertos pensadores en la actualidad, bueno es recordar que ciertamente la revolución de la tecnología de la información se constituye en una herramienta fundamental para generar los procesos de reorganización del sistema capitalista posterior a la década de los años ochenta. De manera que tecnología y desarrollo han planteado por lo menos para un muy importante número de científicos sociales, categorías esenciales de análisis que afirmaban, interrelacionándolos, tanto los modos de producción (estatismo, capitalismo) como los modos de desarrollo (industrialismo, informacionalismo).

Esas nuevas tecnologías, por ejemplo, más allá de las ahora nostálgicas reservas del imperialismo cultural, integran de hecho al mundo en redes globales de información de carácter instrumental que favorecen una nueva forma de socialidad, la sociedad red, caracterizada por esa búsqueda identitaria de diferentes actores sociales a escala planetaria -en parte debido a las promesas incumplidas del Estado nacional- y que se condensan alrededor de formas primarias de socialización, estén o no arraigadas en una historia o en una geografía particular. $\mathrm{O}$ en palabras de $\mathrm{A}$. Touraine, citado por el mismo Castells (2009),

en una sociedad postindustrial, en la que los servicios culturales han reemplazado los bienes materiales en 
el núcleo de la producción, la defensa del sujeto, en su personalidad y su cultura contra la lógica de los aparatos y los mercados, es la que reemplaza la idea de la lucha de clases. (p. 49)

He aquí la importancia que cobra la comunicación en la actualidad, no solo como "vehículo" transmisor de la información sino sobre todo por su carácter ubicuo y sus efectos en la producción de subjetividad: para A. Mattelart (1995), la comunicación sirve fundamental y básicamente para la guerra, pero

por fuera del período de las hostilidades, que suscitan la abundancia de los análisis e incluso su alistamiento al servicio de los ejércitos, la guerra se ha constituido, tradicionalmente, en zona ciega al pensamiento sobre comunicación. (p. 18)

También la comunicación es utilizable como vehículo y vía para el desarrollo, por ejemplo en el informacionalismo de los años ochenta, razón por la cual a partir de esta fecha la comunicación se ha convertido en el progreso, y ha sido sistemáticamente utilizada, por ejemplo en Colombia, como agente de cambio (o como paliativo) y salida al "subdesarrollo"; y como proceso de racionalización de los comportamientos humanos. Y por último, la comunicación es cultura, en la medida en que el mercado-mundo se constituye, asimismo, en un espacio integrador interregional que afecta la constitución misma del Estado nacional, promueve la desterritorialización y genera fenó- menos de reterritorialización, que posibilita que las comunidades recobren las geografías de su singularidad y la seguridad que ofrecen sus espacios primarios de socialización.

\section{- Nuevas formas de estar juntos: cul-} turas juveniles. Jesús Martín Barbero ha interrogado, junto con otros autores, sobre el papel de los procesos socializadores en tiempos contemporáneos, dada la revoltura cultural generada, entre otras situaciones, por el advenimiento de la era de la información y de la ampliación de visiones del mundo que permite a los sujetos. En este sentido, un repertorio amplio de inquietudes se han puesto en la escena de los estudios sociales, inquietudes que transitan -como se había propuesto anteriormente- entre el papel de las instituciones socializadoras clásicas, la fragmentación de la sociedad, la afirmación de la identidad sujeta al territorio o su aparente disolución en formas otras de adscripción al tejido social, en una nueva forma de contrato social que reivindica los microterritorios, las expectativas comunitarias o las adhesiones de coyuntura.

Esos mecanismos de subjetivación en la era de la fluidez y de la modernidad líquida (Bauman, 2000) permiten reconocer una importante diversidad de "formas de estar juntos", sobre todo en el marco de las culturas juveniles de fin del siglo anterior y de los inicios del presente: pandillas, barras bravas, maras, movimientos juveniles, militancias culturales, ideológicas e incluso 
religiosas toman distancia visible de cualquier atisbo de política partidista por inmoral o ineficiente, por corrupta o autorreferencial, por sorda o complaciente. Los motivos de tal desafuero se reconocen en la necesidad de agruparse para construir identidades quebrantadas por el incumplimiento del proyecto moderno, sus referentes, su sentido de pertenencia en una ciudadanía global pero leve; formas de responder a la incapacidad de las instituciones para ofrecer alternativas a una crisis (en el trabajo, en el proyecto de futuro tan largamente prometido, en el sentido mismo de la existencia) cuya única promesa consistía en marginalidad y exclusión. De aquí, también, el porqué de la enorme simpatía que ídolos deportivos y mediáticos, grupos musicales y organizaciones ambientales, reinas de belleza y programas televisivos generan en la población en general, pero de manera sustancial entre los jóvenes, seleccionados como consumidores de importancia por el mercado global pero no exentos de vías alternas, disrupciones y resistencias.

\section{Democracia radical, acción política y resistencia}

Si para Arendt la condición de la vi$d a$ se identifica con la labor, el mundo constituye la condición para el trabajo y la pluralidad condiciona la acción, entendida -como se manifestaba inicialmente-como variedad humana de quienes habitamos el mundo con posibilidad de razón y palabra, la acción política se encontraría esencialmente en el camino de comenzar algo por medio de la acción, a lo que la profesora Arendt (2013) denominó 'natalidad':

El hecho de que el hombre sea capaz de acción significa que cabe esperarse de él lo inesperado, que es capaz de realizar lo que es infinitamente improbable. Y una vez más esto es posible debido a que cada hombre es único, de tal manera que con cada nacimiento algo singularmente nuevo entra en el mundo. (p. 236)

Este subapartado redunda en la premisa de la acción elaborada por la autora alemana, al considerar -en sus propias palabras-que:

La actividad política no es ya considerada como el establecimiento de leyes inmutables que producirían una comunidad y que tendrían como resultado final un producto fiable, el cual se parecería exactamente a como lo hubiese proyectado el fabricador -como si las leyes o constituciones fueran cosas con una naturaleza semejante a la de la mesa fabricada por el carpintero de acuerdo con el proyecto que él tenía en la mente antes de empezar a fabricarlo-. Ahora se supone que la actividad política "produce historia" -una frase que apareció por primera vez en Vicoy no una comunidad, y esta historia tiene, como sabemos bien, su producto final, la sociedad sin clases, la cual constituirá el final del proceso histórico del mismo modo que la mesa es el auténtico fin del proceso de fabricación. (Arendt, 1957)

El camino hacia la materialización de la coexistencia y convivencia armoniosa 
de diferentes puntos de vista en tal polifonía de sentidos plantea el interrogante por la constitución misma del liberalismo político, la neutralidad del Estado y el pluralismo, en el entendido de que es deber del Estado evitar mecanismos represores de las visiones sustantivas de los integrantes de la sociedad, así como estimular la tolerancia por los diversos modos de vida, de manera independiente de su valor intrínseco.

Los acontecimientos de nuestros países en América Latina parecieran apuntar a interrumpir este proceso, si reconocemos que últimamente existe un interés excesivo por intervenir de manera mucho más vigorosa en las decisiones y opiniones colectivas, entre las cuales cabe señalar las manifestaciones en contra de la industria minera multinacional y sus efectos sobre territorios y poblaciones en Chile, Colombia o Bolivia; o de las manifestaciones a favor del aborto como derecho de las mujeres en Colombia; o contra el lucro de la educación, especialmente en Chile y Colombia, o, incluso, las relacionadas contra el matrimonio igualitario en algunos países, las cuales han tenido como soporte y bastión a los gobiernos de turno, a veces para garantizar el modelo neoliberal o, en otras, soportadas por una ideología religiosa que intenta imponer su racionalidad al conjunto de la población.

De aquí que, según Chantal Mouffe (1993),

sólo si se reconoce la inevitabilidad intrínseca del antagonismo se puede captar la amplitud de la tarea a la cual debe consagrarse toda política democrática. Esta tarea, contrariamente al paradigma de "democracia deliberativa" que, de Rawls a Habermas, se intenta imponernos como el único modo posible de abordar la naturaleza de la democracia moderna, no consiste en establecer las condiciones de un consenso "racional", sino en desactivar el antagonismo potencial que existe en las relaciones sociales. (p. 13)

Con lo que -según las palabras de la autora belga- se pasaría de la supresión del antagonismo y su remplazo por el agonismo; de esta manera el enemigo se transformaría en adversario y la construcción de cultura democrática mediada comunicativamente estaría en camino de definirse.

Polémos y polis se ponen en juego aquí como paradojas en la comprensión de lo/la política: por un lado (polémos) como tensión y conflicto, y por el otro (polis) como vivir en conjunto, como estar entre los otros. Y en este sentido Mouffe (1993) va más allá y propone:

El objetivo de una política democrática no reside en eliminar las pasiones ni en relegarlas a la esfera privada, sino en movilizarlas y ponerlas en escena de acuerdo con los dispositivos agonísticos que favorecen el respeto del pluralismo (p. 15).

De ahí que, más allá de la denominada crisis de la democracia deliberativa propuesta por el liberalismo democrático, lo que se pone en discusión es no solo el sentido mismo de la democracia (como autonomía, como 
poder social, como forma de sociedad), sino además la representatividad de los gobiernos, su legitimidad (proporcionada por los resultados electorales), la participación de electores y ciudadanos, las formas de la democracia o sus temporalidades, y, por supuesto, los mecanismos en que los sujetos/ciudadanos actúan en consecuencia de sus intereses y expectativas.

$Y$ en ese mismo sentido anterior se deben ubicar las luchas por la igualdad en el mundo doméstico, individual, que persiguen los sujetos como efecto de los procesos de burocratización y mercantilización de las sociedades y que han generado toda suerte de manifestaciones, movimientos y acciones en pro de la igualdad en una suerte de "revolución democrática" (derechos de minorías éticas y sexuales, derecho ambiental, derecho a la cultura, ampliación de libertades democráticas, etc.) a la que debe seguir, según Laclau y Mouffe (1987), una verdadera demanda por la libertad que garantice la radicalización y pluralización de la democracia:

La demanda de igualdad no es suficiente, sino que debe ser balanceada por la demanda de libertad, lo que nos conduce a hablar de democracia radicalizada y plural. Una democracia radicalizada y no plural sería la que constituiría un solo espacio de igualdad sobre la base de la vigencia ilimitada de la lógica de la equivalencia, y no reconocería el momento irreductible de la pluralidad de espacios. Este principio de separación de espacios es la base de la demanda de libertad. (p. 207)
Que la democracia sea radical significa, en principio, que el poder aparece como un lugar "vacío" en el que navegan tanto las pretensiones de ampliación de la esfera de la autonomía de los sujetos como la extensión y generalización de la equidad: más igualdad, más libertad, más autonomía equivalen, así, a más democracia. $Y$, en el mismo sentido, una promoción aún mayor del debate público y la consecuente participación de los sujetos tanto en la toma de decisiones que afectan a todos los ciudadanos como en la solidez misma que las instituciones requieren para su actuación con el consiguiente fortalecimiento de la democracia y el empoderamiento ( $\mathrm{em}$ powerment) de la sociedad civil.

Algunas de las ventajas adicionales que se podrían destacar de la radicalización de la democracia están relacionadas con los grados de compromiso que las ciudadanías adquieren a partir de las decisiones en materia de política pública, en un ejercicio de politización de los sujetos, amén de una revitalización de partidos, grupos y movimientos que fortalece las relaciones no solo de políticos con ciudadanos sino de instituciones con sus ciudadanos, tan deterioradas por la desconfianza y los abusos de poder de unos sobre los otros.

Pero también se destaca el hecho de que con la radicalización de la democracia se incorporan temas en la agenda política que de otra manera, por ejemplo siguiendo el influjo de los medios de comunicación y sus in- 
tereses, no se discutirían en el ámbito ciudadano; se introduce el veto a las decisiones políticas no queridas por los ciudadanos, como sucede en tiempos hipermediáticos con las opiniones de los ciudadanos/consumidores/ usuarios a través de redes sociales; se debilitan los mecanismos de democracia representativa a mediano y largo plazo, entre un número plural de etcéteras que se podrían considerar.

De aquí, como se puede observar, el porqué de la selección de la antropología política de $\mathrm{H}$. Arendt como piso teórico y conceptual del presente trabajo, que entiende que la igualdad (o semejanza) de los integrantes de la sociedad, de los sujetos que la integran, está en relación directamente proporcional con el hecho de sentirse diferentes, y que justamente esas diferencias se manifiestan en la acción y en el habla y cuya condición humana está claramente definida a partir de un yo determinado por la acción y el discurso: cuerpo, alma, manos.

\section{Resistencia y resistencias en la aldea global}

Sin embargo, también hay que reconocer, en el orden de ideas planteado con anterioridad, que el conflicto, la resistencia, la diversidad de ideas y planteamientos de los sujetos (asociados o no) está en la base de la dialéctica que establece con acciones políticas públicas que ejercen actores colectivos identificables, llámense movimientos obreros de resistencia o movimientos sociales, con acciones de poder de los grupos hegemónicos, los gobiernos o regímenes más o menos arbitrarios o totalitarios.

Tickner y Donjuán (2003) revisan las condiciones del control y la resistencia en el capitalismo global y las formas en que la relación dialéctica poder y resistencia se "traduce" en novedosos mecanismos de control, regulación y disciplinamiento en el consumo cultural, con lo que exponen una reconfiguración respecto del concepto de resistencia en el orden global. Y con ello, evocan el pasaje de las sociedades disciplinarias a las sociedades de control, de las que Michel Foucault (1980) ofreció un panorama -inconcluso hay que decirlo- sobre la idea de gubernamentalidad.

En dicho trabajo, los autores efectúan un recorrido del concepto a partir de la crisis de la modernidad que hiciera la Escuela de Frankfurt, encaminada, como se sabe, a desmontar los supuestos méritos del pensamiento moderno como visión crítica de las lógicas del mundo capitalista, sustentadas en la idea de progreso y del predominio de la razón instrumental a favor de la emancipación humana. Para los críticos frankfurtianos, en especial Adorno y Horkheimer (1998), el racionalismo ilustrado degenera en opresión, barbarie y formas de dominación del hombre contra el hombre, consecuencia del impulso del hombre por dominar la naturaleza; impone valores, también hegemónicos, a través de poderosas industrias culturales que asigna patrones de consumo 
como formas de ejercer el poder; condiciona e instituye el conocimiento como mecanismo de dominación, entre otras situaciones.

La emancipación del hombre frente a la naturaleza se invierte, en el proyecto moderno, como dominio del hombre sobre la naturaleza (sus nefastas consecuencias son hoy motivo, acaso tardío, de preocupación) y como dominación del hombre sobre el hombre en los sistemas de producción.

El consumo, pues, como práctica social y cultural que, arraigada por los ciudadanos/consumidores, oprime, domina, controla y disciplina la moral humana en el actual orden global.

Y en la esquina contraria, las formas de resistir, de escapar o de evadir la dura realidad del orden global: ya sea en la forma de 'etnoescapes' (turistas, refugiados, migrantes), 'mediaescapes' (imágenes del mundo creadas por los media), 'tecnoescapes' (configuraciones de la tecnología en la escala global), 'financiaescapes' (el capital que deambula por la red global de información) o 'ideaescapes' (ideas globales sobre democracia, derechos humanos, libertad, justicia) con que según Appadurai (1996) se ha dado respuesta a los procesos de desterritorialización del mundo (¿post?) moderno.

Estos procesos de dominación, acción y reacción definen, por supuesto, mecanismos y estrategias de resistencia que intentan atenuar o eliminar las marcadas asimetrías que caracterizan las relaciones entre grupos dominan- tes y dominados y que eventualmente impiden que los sujetos puedan expresarse de manera libre y sin presiones, lo que no necesariamente implica actos de rebeldía o mecanismos de protesta pública.

Para Scott (2000), por ejemplo, el discurso oculto de los subordinados y los dominados se hace en la clandestinidad y la discreción ante la mirada del poder, lo que genera otras formas de cultura política asociadas por manifestaciones cotidianas de resistencia en las que la creatividad, la lúdica, la apropiación y reapropiación de la estética hacen juego con estrategias de visibilización y de oposición: ya en las acciones y la retórica neo-punk de grafiteros y artistas callejeros, o en los usos que los consumidores/ ciudadanos/usuarios hacen de las narrativas televisivas, existe una descolonización de los flujos, contenidos y entornos culturales globales; que -asimismo- configuran prácticas cotidianas de hacer como acciones de adaptación y resistencia de aquellos sujetos ausentes de poder.

En los movimientos globales antimundialización neoliberal, en la diversidad de "primaveras" que constituyen respuestas al orden global total, en las manifestaciones en defensa del medio ambiente y en contra de la minería extractiva, en la "democracia en la calle" que reivindica las expectativas de los estudiantes por la educación pública gratuita, de calidad y sin fines de lucro; en el Orgullo Gay 
o la Marcha de la Gorra de Córdoba Capital o, en fin, en la defensa de los derechos de los animales, los derechos religiosos o los derechos a la cultura, en todos ellos la utilización de las 'tácticas' (De Certau, 1996) significan escenarios de movimiento y de "no poder" que pueden ser releídas y resignificadas como una valoración positiva de sus propósitos.

Para Houtart (2001), por último:

La ampliación de las resistencias resulta de la difusión de las consecuencias de la mundialización de la economía capitalista. La feminización de la pobreza implica la radicalización de los movimientos feministas; la destrucción y la privatización de las riquezas ecológicas promueve la creación de grupos de defensa del medio ambiente; las destrucciones culturales suscitan reacciones defensivas a menudo retrógradas cuando éstas no están acompañadas de un adecuado análisis.

La fragmentación es el fruto de las divisiones geográficas y sectoriales. Mientras que las bases materiales de la reproducción del capital, sobre todo del financiero (que dominó la fase neoliberal de la acumulación capitalista contemporánea), reposan cada vez más en el plano mundial, las resistencias son aún esencialmente locales. Los últimos sucesos han revelado sin embargo una tendencia a las confluencias, aun si éstas son todavía difíciles por falta de recursos, aunque Internet brinda hoy la oportunidad de nuevas posibilidades de comunicación. (p. 65)

La razón de ser de este ensayo no se limita a los horizontes de sentidos y propósitos de las resistencias, sino que también busca comprender el carácter festivo de las manifestaciones, las reapropiaciones y resignificaciones que sobre el poder, la justicia, la legitimidad y los derechos hacen los sujetos en diferentes espacios, entre ellos, el escenario anárquico de Internet.

\section{Sociedad red y movimientos sociales}

Para Tilly (2008),

los movimientos sociales nacieron con el proceso de democratización parcial que llevó a los súbditos británicos y a los colonos norteamericanos a plantar cara a sus gobernantes en el siglo XVIII. A lo largo del siglo XIX, los movimientos sociales florecieron y prosperaron, por lo general, allá donde se estaban dando más pasos en pro de la democratización, y retrocedieron en aquellos lugares en los que los regímenes autoritarios recortaban los derechos democráticos. Este patrón se mantuvo durante los siglos XX y XXI: el mapa de los movimientos sociales consolidados se solapa en muchos casos con el de las instituciones democráticas. (p. 15)

Y continúa:

Con todo, también hemos aprendido que los movimientos sociales no fomentan ni defienden necesariamente la democracia. Es mucho más habitual que los movimientos nazcan alrededor de un interés o de un agravio que de las reivindicaciones democráticas como tales. (p. 15)

Dichas afirmaciones conducen a pensar que existe un destiempo entre 
democracia y movimientos sociales, que no hay coexistencia entre las dos situaciones y que no hay evidencia que permita concluir la relación existente entre movimientos sociales y democracia; aunque los procesos de democratización aportan, sin duda, al fomento y proliferación de los movimientos sociales como consecuencia de formas específicas de asociación a través de reuniones públicas y manifestaciones colectivas que estimulan la aparición de otras instituciones, entre las cuales se encuentran los sindicatos o los partidos políticos, que facilitan las reivindicaciones del movimiento social.

A su turno, y apelando a la conflictividad como elemento esencial de lo social, el sociólogo Alain Touraine (1999) afirma que "el movimiento social es la conducta colectiva organizada de un actor luchando contra su adversario por la dirección social de la historicidad en una colectividad concreta" (p. 56). Para lograr este propósito, el autor francés sugiere no separar las orientaciones culturales del conflicto social, situado en el interior mismo de la vida social, como contramodelos o paradigmas que se oponen a las decisiones hegemónicas de los grupos dominantes. Acciones que, siguiendo la ruta trazada por Touraine, no están necesariamente dirigidas en su fundamento a contrarrestar al Estado como acciones políticas por la conquista del poder, pero sí como reconfiguraciones de ese poder.

En suma, los movimientos sociales en la literatura seleccionada se diferen- cian notablemente de otros formatos de hacer política, como las campañas electorales, los acuerdos o las negociaciones, por la combinación de algunos factores, entre los que cabe destacar: campañas en defensa de demandas colectivas, actuaciones de carácter público que incluyen demandas a través de manifestaciones, contacto con la prensa, creación de redes y asociaciones, coaliciones con otros grupos significativos de la sociedad (sean estos partidos políticos congruentes con el conflicto, sindicatos o gremios) $y$, finalmente, muestras coherentes y ordenadas de lo que Tilly (2008) denomina WUNC (worthiness, unity, numbers, commitment), es decir, "valía, unidad, número y compromiso" de los activistas comprometidos en el movimiento. A ese repertorio de características habría que añadirle los mecanismos no convencionales en los que se despliegan las actividades de los movimientos sociales, el uso de símbolos y nuevas narrativas culturales y estéticas que permiten, lo que para algunos autores sugiere resignificaciones de las formas dominantes de interpretar la realidad y recursos de (re)apropiación de la realidad cultural de los sujetos.

Con estos propósitos en juego, que incluyen, por supuesto, la generación de un importante grado de aceptación de parte de la comunidad a través de mecanismos de persuasión e influencia, es indudable que la comunicación de sus aspiraciones juega un papel preponderante para el logro de sus 
proyectos. Es aquí donde medios alternativos de comunicación y formatos audaces de divulgación y circulación de sus ideas se conjugan con la creatividad, la lúdica y el carácter festivo de sus manifestaciones.

Las acciones de estos grupos están, lógicamente, influenciadas por las oportunidades derivadas de las situaciones que les ofrece la coyuntura (porque, se recuerda, los movimientos sociales son ante todo reacciones frente a un estado de cosas imperante), reconocidas como oportunidades políticas ante las cuales se responde con actuación e intervención. La manera en que se despliegan estos "repertorios de confrontación" (Martí i Puig y Sanahuja, 2004) pertenece al ámbito de las culturas políticas propias de los grupos, aunque en el orden informacional global en sociedades contemporáneas estos mecanismos de resistencia hayan determinado rutinas más o menos estables y coincidentes de acción colectiva, lo que se evidencia en el hecho de que las prácticas sociales aunadas a los movimientos sean tan semejantes.

Con todo, se debe coincidir en que la acción colectiva empleada por los movimientos sociales tiene como finalidades la comunicación y transmisión de sus exigencias como ejercicio de exteriorización de demandas, que por otras vías quedarían invisibilizadas por los grupos de poder; la generación de sentimientos de solidaridad no solo de parte de los activistas sino de la sociedad, elemento constitutivo que garantiza los vínculos de los líderes con los seguidores; la convicción de la ciudadanía a través de sentimientos identitarios $y$, finalmente, la posibilidad de generar incertidumbre a raíz de las acciones que realizan.

$\mathrm{Y}$ es justamente en ese contexto, en el de la sociedad informacional, en el que se mueven tanto los movimientos sociales como la sociedad red, definida por Castells (2009) como

\begin{abstract}
aquella cuya estructura social está compuesta de redes activadas por tecnologías digitales de la comunicación y la información basadas en la microelectrónica. Entiendo por estructura social aquellos acuerdos organizativos humanos en relación con la producción, el consumo, la reproducción, la experiencia y el poder expresados mediante una comunicación significativa codificada por la cultura. (p. 50)
\end{abstract}

Sistema en redes cuya capacidad de autorreconfiguración se encuentra en sintonía con la trascendencia de límites territoriales e institucionales en las que las actividades básicas -aunque no participen directa y activamente en las redes- se ven afectadas de una manera $u$ otra en sus dinámicas de producción, gestión, administración, interacción, creación o decisión, situaciones propias de los movimientos juveniles latinoamericanos que -inscritos en esta lógica y atravesados por internet como tecnología y como cultura- reconfiguran las prácticas de acción política en las sociedades contemporáneas. 
A manera de síntesis, el artículo recorre, con $\mathrm{H}$. Arendt, su concepto de acción con el fin de insistir en su carácter definitorio para concebir la condición humana, que las formas de acción humanas se han visto reconfiguradas por las dinámicas de las sociedades contemporáneas y que esas variaciones implican el reconocimiento de otras formas de pensar la democracia, el mundo y la acción social en tiempos de renovadas maneras de concebir el mundo.

\section{Referencias}

Adorno, T., y Horkheimer, M. (1988). Dialéctica del iluminismo. Buenos Aires: Sudamericana.

Appadurai, A. (1996). Modernity at large. Cultural dimensions of globalization. Minneapolis: University of Minnesota Press.

Arendt, H. (1957). Labor, trabajo y acción. (Conferencia). En The papers of Hannah Arendt. Recuperado de http://web cache.googleusercontent.com/ search?q=cache:brpqEi1iS5gJ:www. balearweb.net/afibfilosofia/docs /Arendt.\%2520Labor,\%2520trabajo $\% 2520 y \% 2520$ accion.doc $+\& \mathrm{~cd}=1 \& \mathrm{hl}$ $=\mathrm{es} \& \mathrm{ct}=\mathrm{clnk} \& \mathrm{gl}=\mathrm{cO}$

Arendt, H. (2013). La condición humana. Buenos Aires: Paidós.

Bárcena, F. (2006). Hannah Arendt: Una filosofía de la natalidad. Barcelona: Herder Editorial.

Bauman, Z. (2000). La modernidad líquida. Buenos Aires: Fondo de Cultura Económica.
Borja, R. (2007). Sociedad, cultura y derecho. Quito: Planeta.

Castells, M. (2009). Comunicación y poder. Madrid: Alianza Editorial.

Cortina, A. (2010). Las raíces éticas de la democracia. Valencia: Universitat de València.

Foucault, M. (1980). Vigilar y castigar. Nacimiento de la prisión. Bogotá: Siglo XXI Editores.

García Canclini, N. (1995). Consumidores y ciudadanos: conflictos multiculturales de la globalización. México, D. F.: Grijalbo.

Houtart, M. (2001). Mundialización de las resistencias. Estado de las luchas. Bogotá: Ediciones Desdeabajo.

Laclau, E., y Mouffe, Ch. (1987). Hegemonía y estrategia socialista. Hacia una radicalización de la democracia. Madrid: Siglo XXI.

Martí i Puig, S., y Sanahuja, J. M. (eds.). (2004). Etnicidad, descentralización y gobernabilidad en América Latina. Salamanca: Ediciones Universidad de Salamanca.

Mattelart, A. (1995). La invención de la comunicación. Barcelona: Siglo XXI.

Mouffe, C. (1993). El retorno de lo político. Comunidad, ciudadanía, pluralismo, democracia radical. Barcelona: Paidós.

Scott, J. C. (2000). Los dominados y el arte de la resistencia. Discursos ocultos. México: Ediciones Era.

Tickner, A., y Donjuán, E. (2003). Capitalismo, control y resistencia. Revista Colombia Internacional, 55, 55-74. 
Tilly, Ch. (2008). Los movimientos so- $\quad$ Touraine, A. (1999). ¿Cómo salir del libeciales entran en el siglo veintiuno. ralismo? México, D. F.: Paidós.

Política y Sociedad, 2(42), 11-35. 